\title{
Anticipating Alternative Futures for the Platform Economy
}

\author{
Mikko Dufva, Raija Koivisto, Leena Ilmola-Sheppard, and Seija Junno
}

\author{
"Platforms are online environments that take advantage" \\ of the economics of free, perfect, and instant. \\ Andrew McAfee and Erik Brynjolfsson \\ Authors of Machine, Platform, Crowd \\ and The Second Machine Age
}

\begin{abstract}
Despite the considerable hype around platforms, our understanding of what the platform economy means and what drivers will define future development trajectories is limited. Companies and policy makers have a great need to investigate what potential opportunities will arise from the platform economy. A shared perception of uncertainties and a strong vision are prerequisites for the development of the platform economy. In this article, we describe a systematic way to develop a resilient vision for a new platform ecosystem, both from the viewpoint of national policy makers and corporate strategy makers in the heavy engineering industry. The process uses morphological analysis for scenario development and robust portfolio modelling for creating resilient strategies. The results include a list of key uncertainties, three general scenarios (sustainable development by Europe; polarization driven by China and the United States; US-driven fast, unreliable growth) as well as steel-industry specific scenarios based on these uncertainties, elements of a resilient vision, and strategies for coping with the uncertainties described by the scenarios.
\end{abstract}

\section{Introduction}

There are signs of a major transformation taking place in the structure of the global economy. The quickly emerging developments lead towards a networked, digital-platform-based mode of operating: the platform economy (see e.g., Parker et al., 2016; van Alstyne et al., 2016). Although there are many definitions of what a platform is, in this article, we adopt the platform-asecosystem view, which emphasizes the transactions between actors (see e.g., Thomas et al., 2014). By platform, we refer to a digital ecosystem that is a loosely coupled activity system organized around a digital platform, within which different actors (producers, users, related supporting service providers) flexibly create and combine offerings (modified from Autio et al., 2016). Consequently, we define the platform economy as the value creation system consisting of platforms.

Widely known examples of platforms include Uber and AirBnB - or IBM Watson and John Deere in the B2B domain - but the platform economy goes beyond just connecting users and producers. Platforms have production, innovation, and transaction leverage, meaning they can use resources more efficiently and generate value through network effects (Thomas et al., 2014). Platforms necessitate the rethinking of strategies and business models (Eloranta \& Turunen, 2016; Evans, 2003; Parker et al., 2016), and they pose new challenges for regulators (Acquier et al., 2017; Edelman \& Geradin, 2015; Murillo et al., 2017).

In the platform economy, the value depends on the extensiveness and functioning of the network (Evans et al., 2011; Parker et al., 2016, Thomas et al., 2014). Companies provide services for connecting actors around an activity or need, and they enable them to collaborate, allocate and use resources more efficiently, and cocreate value for each other. Parker, Van Alstyne, and Choudary (2016) argue that companies must embrace platform thinking to ensure their future survival: "practically any industry in which information is an import- 


\section{Anticipating Alternative Futures for the Platform Economy}

Mikko Dufva, Raija Koivisto, Leena Ilmola-Sheppard, and Seija Junno

ant ingredient is a candidate for the platform revolution". According to a study by Accenture, $88 \%$ of the Fortune 500 companies are investing in platforms (Lacy et al., 2016). Their motivation emerges from the finding that digital platform businesses are growing faster than other companies in the market. The platform economy both threatens to disrupt industries and promises new and rapidly growing markets (Acquier et al., 2017).

Nonetheless, companies that are initiating a platform ecosystem are facing a major challenge. The development of the platform economy is clouded by major uncertainties regarding not only technology development but also geopolitical power structures, the role of public and private actors, developments in regulatory environment, and the structure and development of the global financial system. These uncertainties have not been systematically taken into account when thinking about future developments in the platform economy. Furthermore, a company-specific analysis is able to reveal only a narrow part of the phenomenon. The true transformative capacity is in the nature of the ecosystem of this new economic structure, and this ecosystem consists of and is impacted by many actors, not just the (incumbent) companies. For example, open platforms (Gawer \& Cusumano, 2014) are generating fast, co-evolving ecosystems that are able to challenge dominant players in global markets. In addition to companies, also governments (e.g., the United States, Japan, the United Kingdom, South Korea, and the European Union; OECD, 2017) are eager to capture a share of the global platform business and are building their own platform policy strategies.

We argue that the resilience requirements of platform ecosystem vision, structure, and strategy deserve greater attention both on the general level as well as from the viewpoint of a company. Strategic planning can meet the challenges related to uncertainty with anticipation and resilience building (Ilmola \& Rovenskaya, 2015). Given that the line of development is highly uncertain, strategic planning requires ways to manage uncertainties and build resilience (Daft \& Weick, 1984; Folke, 2006; Taleb, 2007). The key to more resilient operations is to define what the strategy should be resilient to. Scenarios are a way to define alternatives if they cover a sufficiently comprehensive range of potential futures.

The main research question in this article is "What are platform ecosystem options within different global plat- form economy scenarios?" By global platform economy scenarios, we mean alternative descriptions of futures of the platform economy as a whole. On this general level, the goal is to improve our understanding of the drivers of the emerging phenomena of the platform economy and its related uncertainties, and to support industry and society in deriving benefits from it. In addition to describing these global development scenarios, we translate them into industry-specific narratives based on a case study in the Finnish steel industry. The case study was a very specific example of platform ecosystem development. There are thus two levels of analysis: the general scenarios and their implications, and industry-specific developments and options.

\section{Methods}

Our research question requires a method that captures the main uncertainties and - in order to secure and improve resilience - produces alternative, mutually exclusive scenarios that cover a wide range of possibilities. We thus decided to use a morphological analysis (Ritchey, 2011), which is a systematic method for considering multiple uncertain factors. In morphological analysis, key factors of uncertainties are identified, possible alternative exclusive states for each factor are developed, the pairwise compatibility of each state is assessed (i.e., determining whether two states are in conflict with each other), and finally, alternative coherent scenario structures are produced. In addition, we used expert workshops, scenario writing, and portfolio modelling to refine the scenarios and assess alternative options for responding to the challenges posed by the scenarios. In parallel to the development of global platform economy scenarios, we interpreted them in the context of the steel industry with a company interested in initiating a platform ecosystem around their products and services. Below, we describe in detail both the development of the global platform economy scenarios and the case study.

\section{Scenario development}

The scenarios were developed during 2016 in a multisector participatory foresight process together with 20 experts from universities, corporations, and government. Eleven members of the expert group were researchers that represented two cross-disciplinary research projects funded by Finland's Strategic Research Council: one focused on platform business models and management and the other on the technical aspects of the Internet of things (IoT) and the platform economy. In addition to the researchers, the expert 


\section{Anticipating Alternative Futures for the Platform Economy}

Mikko Dufva, Raija Koivisto, Leena Ilmola-Sheppard, and Seija Junno

group included corporate strategy planners (5) and senior policy and strategy planners (4) from the Ministry of Economic Affairs and Employment and the Finnish Funding Agency for Technology and Innovation (TEKES). The process used both online surveys and face-to-face workshops (Figure 1).

Key uncertainties related to the development of the platform economy were identified via a web-based questionnaire, which the expert group answered prior to the first workshop. The questionnaire included three open-ended questions, such as "Think about industrial internet and platform ecosystems in global services and industries. What drivers are shaping their development?" (by driver we mean a description of factors and issues that influence the development of platform economy) and "Can you think of something unclear but potentially important that is going on in the development?" The question format is specially developed for scanning early signs of change (Ilmola \& Kuusi, 2013). For each question, the respondents could input as many drivers as they wanted, in the format of title and description. The questionnaire then asked respondents to assess the importance of drivers others had provided by placing them closer or further to the centre of an evaluation board (Figure 2).
Altogether, 153 drivers of digital platform development were collected and assessed. The assessment process produced a group of drivers that the respondents agreed to be either very important or not important at all (representing the dominating mental model of the development; see Ilmola \& Kuusi, 2013), and two groups of drivers where opinions differed between experts. The importance of each driver was calculated by measuring its distance from the centre of the evaluation board. (Further details of the method are described in Ilmola and Kuusi, 2013). The first group of differing opinions - called emergent drivers - were those that had a high standard deviation (assessments varied substantially) as well as relatively high importance (measured as the mean of answers). The second group called weak or early drivers - were those whose importance was perceived to be high only by a few experts. This assessment helped to identify key drivers as well as sources of disagreement among the experts, which can be an indication that the driver should be further explored.

The results were further developed into scenarios in the first expert workshop. The key drivers and related uncertainties were clustered into dimensions for a morphological analysis (Ritchey, 2011) by the core research

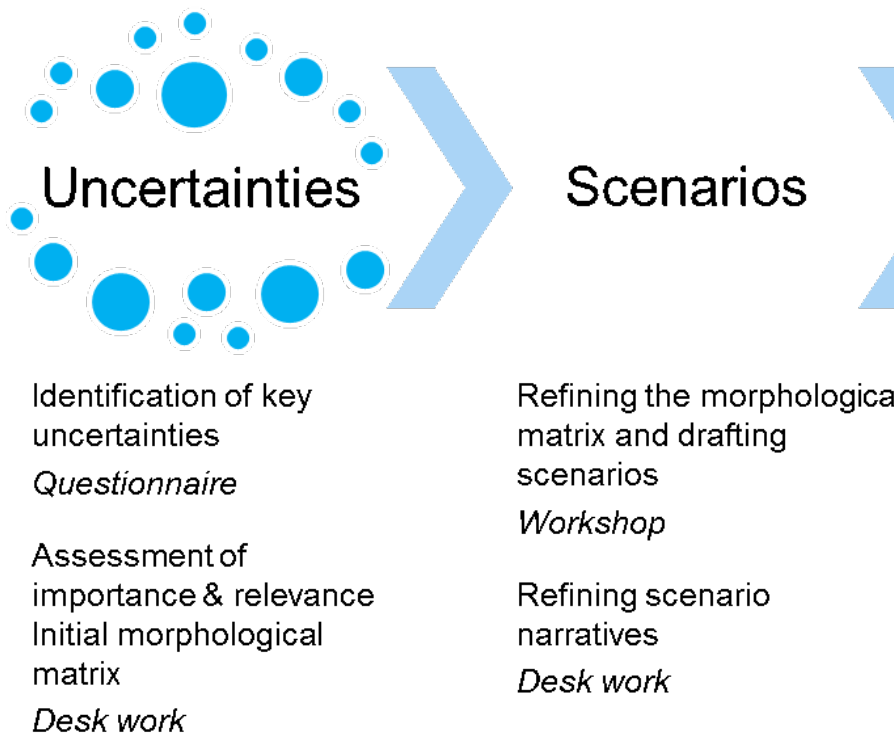

\section{Strategies}

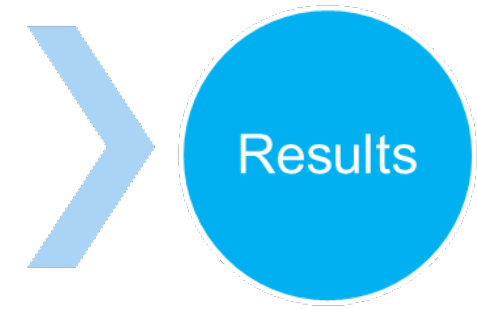

Collection and
assessment of options
and strategies
Questionnaire
Refining scenarios and
strategies
Workshop

Identifying resilient strategies with Robust

Portfolio Modelling

Desk work
Synthesis and presentation

Desk work

Figure 1. Scenario development process 


\section{Anticipating Alternative Futures for the Platform Economy}

Mikko Dufva, Raija Koivisto, Leena Ilmola-Sheppard, and Seija Junno

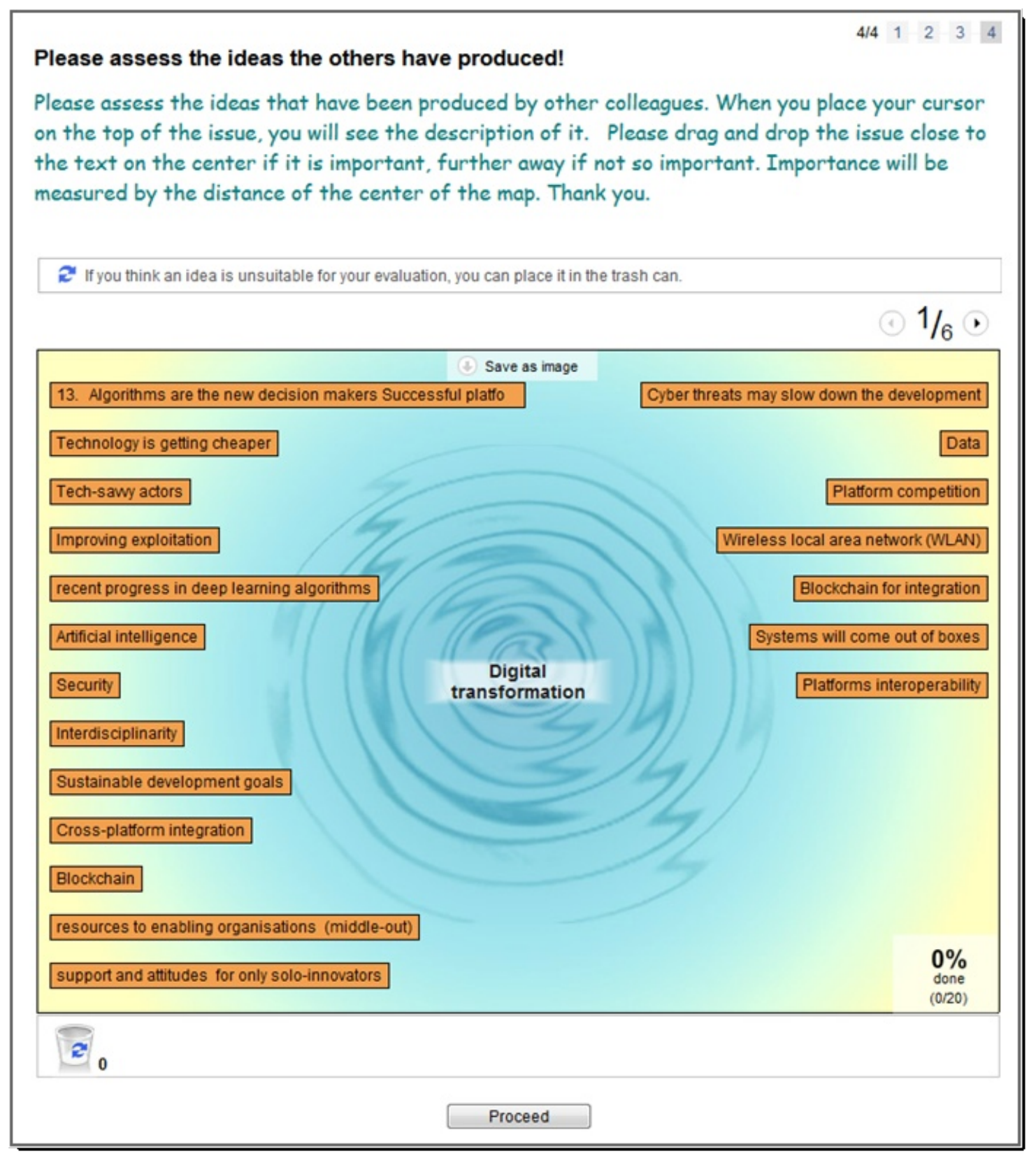

Figure 2. Assessing the answers of other experts

group, who used the STEEP framework (social, technological, economic, environmental, and political drivers) to produce an initial grouping according to key dimensions. Each of the dimensions was described with mutually exclusive alternative states and was collected to form the morphological matrix (Figure 3). Special attention was paid to the independence of the drivers, to the coherence of the driver state combinations, and to the diversity and novelty of resulting scenarios. Thus, the morphological matrix was discussed and refined iteratively during the workshop. The experts also created initial scenario drafts based on different combinations of the driver states, which were produced with the help of the Parmenidos EIDOS software to ensure coherence and diversity. After the workshop, the scenario drafts were written out as narratives by the core research group. 


\section{Anticipating Alternative Futures for the Platform Economy}

Mikko Dufva, Raija Koivisto, Leena Ilmola-Sheppard, and Seija Junno

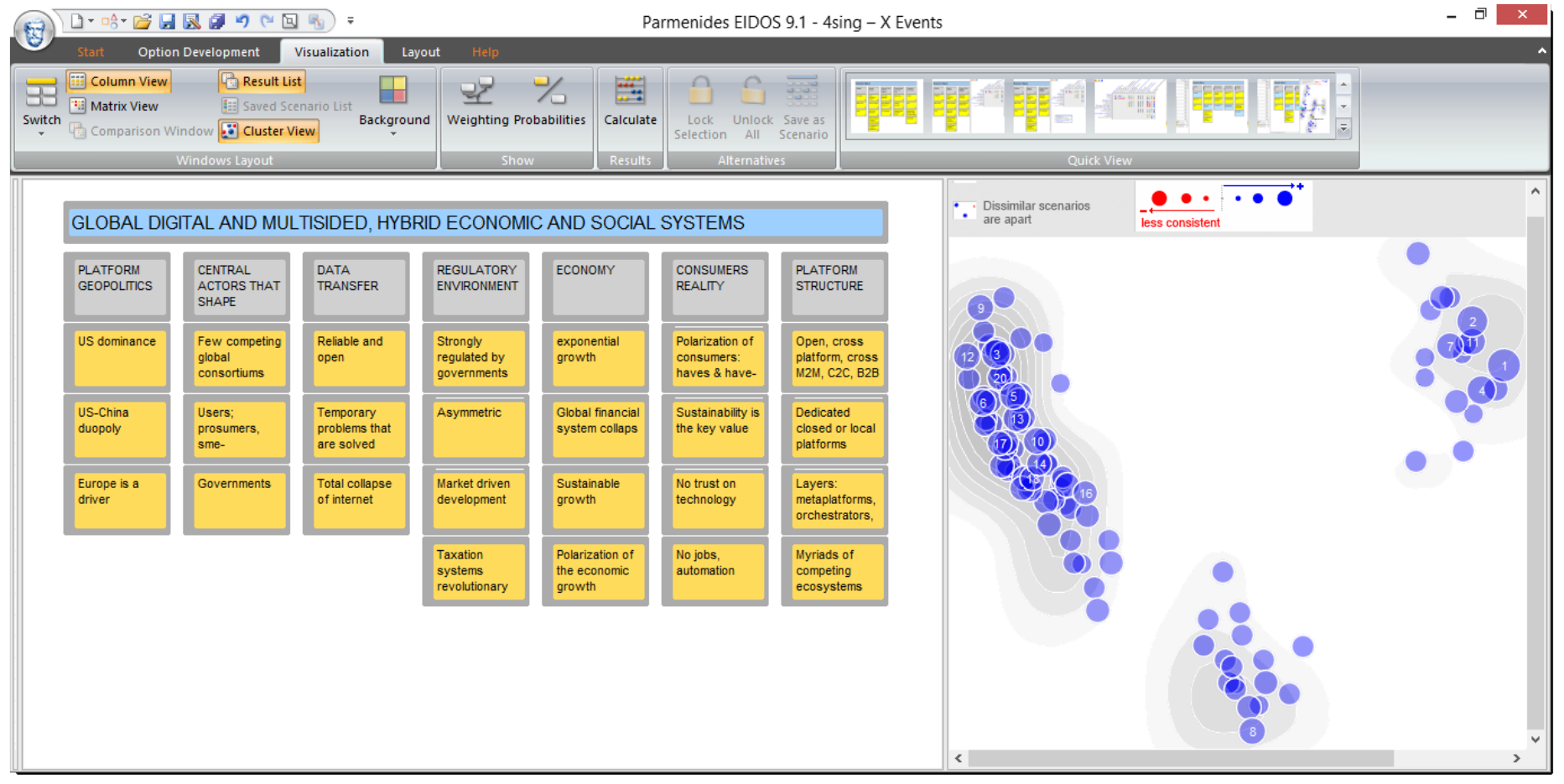

Figure 3. Key uncertainties in the platform economy and their alternative developments

A second web-based questionnaire was used to gather different strategic and policy actions for succeeding in the platform economy and to assess them in the different scenarios. These actions as well as the scenarios were discussed and further developed in a second expert workshop. In addition to refining the scenario stories, the workshop participants generated success strategies consisting of various actions for each of the scenarios from various industrial perspectives. After the workshop, the actions were prioritized and their resilience analysed using robust portfolio modelling (RPM) (see e.g., Liesiö et al., 2008). RPM is a decision-support methodology used for analyzing multi-criteria portfolio problems (Ilmola \& Rovenskaya, 2016; Lourenço et al., 2012). It uses standard decision-analysis models to capture the benefits of different options and option portfolios (i.e., option combinations), but also admits incomplete information about the parameters. Based on combinatorial optimization techniques, the RPM identifies feasible and efficient option portfolios (i.e., those that satisfy relevant portfolio constraints regarding limited resources). RPM supported the identification of actions that are successful across the scenarios. Thus, we were able to define a set of resilient actions that would be useful in all of the scenarios analyzed. That outcome we call a resilient strategy.
Case study: Scenarios for the SmartSteel platform

The generic platform economy scenarios were customized by applying the morphological analysis presented above for a sector-specific case context, focusing on heavy engineering value chain. The project team had an opportunity to work in close collaboration with a consortium that had an ambition to develop a platform that covers the whole value chain and lifecycle of a steel product. In practice, this could mean, for example, all the phases from steel production to building a luxury cruise ship, and further to the phase where the ship is wrecked and the material is recycled.

The consortium participants had a strong business focus, and the main objective of the scenario exercise was to generate and compare different business models needed in scenario environments. Thus, the final market-specific scenarios had different titles that reflected technology development instead of geopolitics, such as "Internet Havens", "Fast Transitions", and "Technology Stuck in Tar". Whereas the global platform economy scenarios focused on global and general developments and national level policy options, the industry-specific ecosystem scenario work focused on analyzing different business models that would produce success in each of the scenarios. The outcome was a vision and 


\section{Anticipating Alternative Futures for the Platform Economy}

Mikko Dufva, Raija Koivisto, Leena Ilmola-Sheppard, and Seija Junno

strategy for a SmartSteel platform. It consisted of elements that were assessed to be resilient both in the long term and in the short term, that is during the ecosystem business development phases.

\section{Results}

This section describes the three main outcomes of the process: the identified uncertainties, scenarios based on these uncertainties, and strategies for coping in the world described by the scenarios. We first describe results related to the general developments in the platform economy and then the case-specific results.

Key global uncertainties and possible development paths for platform ecosystems

The development of the platform economy is shrouded by major drivers that have many potential states. These represent key uncertainties that have a major impact on platform ecosystem development and to the choice of technology and ecosystem-level coordination. The participatory process described earlier identified seven main uncertainties that characterize the development of the platform economy, and alternatives for each of them were defined (Figure 3). The seven uncertainties cover key changes in the political, economic, social, and technological environments:

1. Platform geopolitics: The United States has dominated the platform business globally and especially in the Western countries. China is another big player driven by its fast platform development. Europe is lagging behind, but is taking a slightly different approach with emphasis on privacy and developing practices for the fair ownership of data. There are signs of the European Union challenging the practices of US-based platforms through regulation. How these geopolitical tensions play out is crucial in determining the future nature of the platform economy. For the scenarios, three alternatives were defined: US Dominance; US-China duopoly; Europe is a driver.

2. Central actors: The platform economy is currently largely driven by companies that have been able to scale up quickly and thus enjoy network effects. There is a tendency towards greater integration and platforms taking on new functionalities. There is also a countertrend with a focus on user-owned platforms or platform cooperatives as well as more local platforms. Governments are also taking more active roles in the development of the platform economy.
Thus, the key question is: who is the key player in determining the development of the platform economy? Three alternatives were defined: Few competing consortiums; Users, prosumers, SMEs enabled by blockchain; Governments.

3. Data transfer: The platform economy is being built upon ubiquitous, accessible, reliable, and global data transfer. However, there are many developments that challenge the reliability of Internet and digital data transfer. There have been increasing numbers of attacks on domain name servers. There is also increasing volumes of traffic and numbers of devices, which both strain the infrastructure. The debate on net neutrality is also ongoing, with some service providers wanting to favour more lucrative traffic. Three alternatives were defined for how data transfer develops: Reliable and open; Temporary problems that are solved; Total collapse of the Internet.

4. Regulatory environment: Platforms disrupt existing industries and challenge the conventional notion of an employee. They also raise new questions about privacy and the ownership of data. Governments and communities have taken different approaches towards disruptive platforms. In the scenario process, four alternative pathways for the development of regulatory environment were defined: Strong regulation by governments; Asymmetry where the strictness of regulations varies between sectors and regions; Market-driven development; New forms of taxation.

5. Economy: The general development of the economy of course influences the future of the platform economy. The big question, especially in Europe, is stagnation or even the collapse of the whole economic system. On the global level, the polarization of growth is a key uncertainty: where will growth continue and where will it not? In the scenario process, four alternative developments for the economy were defined: Exponential growth; Global financial system collapse; Sustainable growth; Polarization of economic growth.

6. Consumers' reality: The values and attitudes of consumers or users of the platforms are key in defining how the platform economy develops. Platforms have the potential to connect and empower people as well as disconnect them from "filter bubbles". So far, the platforms have probably increased inequality more than they have reduced it because of the dominance of "winner takes all" dynamics. Four alternatives 


\section{Anticipating Alternative Futures for the Platform Economy}

Mikko Dufva, Raija Koivisto, Leena Ilmola-Sheppard, and Seija Junno

were defined related to consumers' reality: Polarization of consumers; Sustainability is the key value; No trust on technology; No jobs.

7. Platform structure: Currently, the dominant platform structure is rather closed with few application program interfaces (APIs) for interaction with other services. Data is usually owned by the platform and is often difficult to extract. There are also signs of open and distributed platforms as well as metaplatforms, which act as a "platform of platforms". Four possible structures were defined for the scenarios: Open; Dedicated closed or local; Layers and metaplatforms; Myriad of competing ecosystems.

\section{Scenarios}

Based on the key uncertainties, three scenarios were elaborated in the workshops. The selection of the development paths for each scenario was assisted with software to ensure the internal coherence and diversity of the scenarios (Figure 4). A sketch of each scenario is provided below:

\section{- Scenario I: Polarization driven by China and the US.} Chinese and American companies are ruling the global economy. They have built gigantic consortiums that have a portfolio of various platforms that they play with. Regulation is weak and the markets are leading development. Automation is well advanced and applied widely, and that has a strong impact on employment. Many have lost their jobs, but the minority of specialists that are still needed are doing very well. All seems to be fine, until the Internet has an increasing number of failures. Large companies are building their own closed worldwide networks. Those consumers that are not potential customers for global companies are dropping off.

- Scenario II: Sustainable development by Europe. The impacts of climate change and global warming are visible everywhere. Consumers and political decision makers are ready for behavioural change, and sustainability is dominating decision making at all levels. The climate is warming, but at the same time, the geopolitical atmosphere is freezing. Countries, especially the US, are using large companies' data against international codes of conduct. In the scenario, users have lost their confidence in American companies after several scandals, and they highly appreciate European platforms, which they perceive as trustworthy. Even if the growth of the economy is still modest, the interoperability of open platforms based on European standards generates a high economic potential.
- Scenario III: US-driven, fast, unreliable growth. The US is still the engine of the global economy, especially when Chinese and African economies are struggling with the side effects of the recent superfast growth periods. With President Trump, the US political context is refocusing and anti-trust regulation - and especially the financial support for the digital infrastructures - favour networks of small and mediumsized companies. Unlike in 2016, the markets now consist of fast-growing and fiercely competing platforms. Global infrastructure is not receiving investment, and overheated Internet traffic leads to collapse. Secure, closed network providers are collecting platforms under their wings.

\section{Case-specific market-focused scenarios}

The value-chain-specific scenarios included the same dimensions, but in a simplified way. Key dimensions of the market-specific scenarios were technology development, globalization, Internet development, politics, and consumer values. Based on these dimensions, three case-specific market scenarios were developed: "Internet Havens", "Technology Stuck in Tar", and "Fast Transitions" (Figure 5).

The group generated visions for each of the scenarios. These visions consisted of scenario-specific choices of structure of the ecosystem, its governance model, and

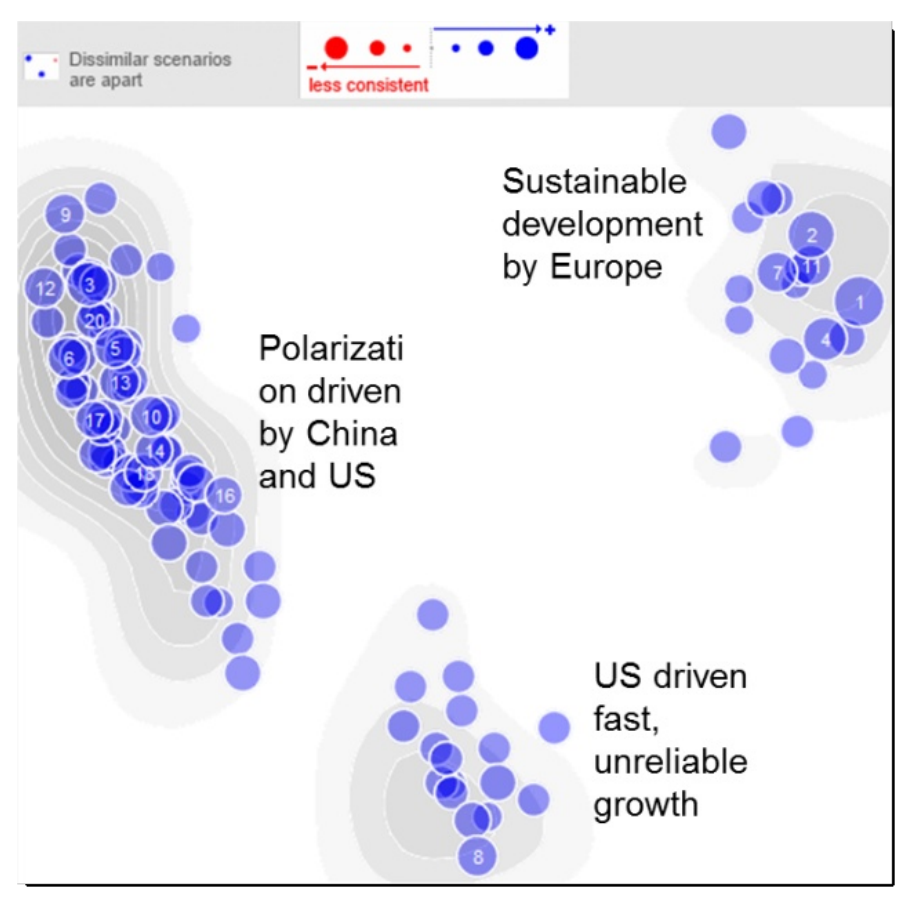

Figure 4. The alternative combinations of dimension states produced a large set of alternative scenarios 


\section{Anticipating Alternative Futures for the Platform Economy}

Mikko Dufva, Raija Koivisto, Leena Ilmola-Sheppard, and Seija Junno
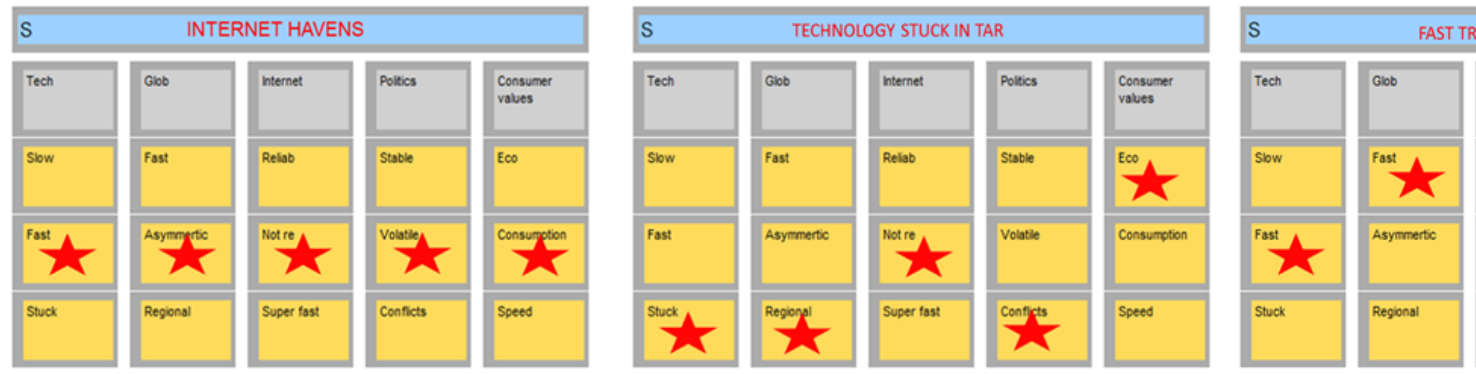

FAST TRANSITION
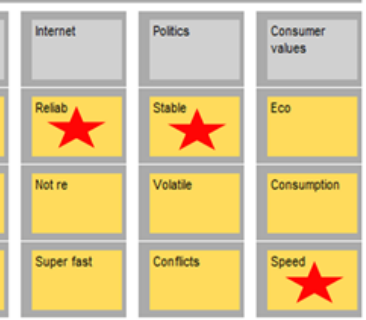

Figure 5. Three market-specific scenarios

the focus market. The vision described the growth pattern as well. Visions were operationalized into a set of actions that consisted of technology development, regulatory lobbying, and acquisition of specific knowledge needed.

Resilient strategies and key recommendations

The robust portfolio analysis (RPM) produced a propos- ition of actions that would be useful across all of the scenarios defined. The results are presented in Figure 6. The resilience testing for the SmartSteel platform case study included 23 actions from certification to early investments. Typical for resilient actions was a low investment requirement and close relatedness of the current customer needs. Full details are not disclosed due to confidentiality.

\begin{tabular}{|lr|}
\hline \multicolumn{2}{|c|}{$\begin{array}{c}\text { Actions' impacts on scenario } \\
\text { probabilities taken into account }\end{array}$} \\
\hline EU steel legislation & 1.00 \\
\hline Platform investment & 1.00 \\
\hline Information security & 0.92 \\
\hline Certification & 0.92 \\
\hline Speed and agility & 0.92 \\
\hline Service business & 0.77 \\
\hline New sources of income & 0.77 \\
\hline Open interfaces & 0.62 \\
\hline Traceability requirements & 0.38 \\
\hline Partnering & 0.38 \\
\hline Central corporation / foundation & 0.31 \\
\hline Early investments & 0.00 \\
\hline Cost savings & 0.00 \\
\hline Sustainability requirements & 0.00 \\
\hline Sector-focused development & 0.00 \\
\hline Institutional actors & 0.00 \\
\hline Technology business & 0.00 \\
\hline No novel technologies & 0.00 \\
\hline Passive location tag & 0.00 \\
\hline Active tag & 0.00 \\
\hline Energy storage tag & 0.00 \\
\hline Antenna capability & 0.00 \\
\hline Sensor layer for loT & 0.00 \\
\hline
\end{tabular}

\begin{tabular}{|lc|}
\hline \multicolumn{2}{|c|}{$\begin{array}{c}\text { Actions' impacts on scenario } \\
\text { probabilities neglected }\end{array}$} \\
\hline EU steel legislation & 1.00 \\
\hline Platform investment & 1.00 \\
\hline Information security & 1.00 \\
\hline Partnering & 1.00 \\
\hline New sources of income & 0.68 \\
\hline Traceability requirements & 0.56 \\
\hline Open interfaces & 0.52 \\
\hline Central corporation / foundation & 0.52 \\
\hline Certification & 0.48 \\
\hline Service business & 0.48 \\
\hline Sector-focused development & 0.30 \\
\hline Speed and agility & 0.30 \\
\hline Institutional actors & 0.14 \\
\hline Sustainability requirements & 0.02 \\
\hline Technology business & 0.00 \\
\hline No novel technologies & 0.00 \\
\hline Passive location tag & 0.00 \\
\hline Active tag & 0.00 \\
\hline Energy storage tag & 0.00 \\
\hline Antenna capability & 0.00 \\
\hline Sensor layer for loT & 0.00 \\
\hline Early investments & 0.00 \\
\hline Cost savings & 0.00 \\
\hline
\end{tabular}

Figure 6. Computation results from the robust portfolio model 


\section{Anticipating Alternative Futures for the Platform Economy \\ Mikko Dufva, Raija Koivisto, Leena Ilmola-Sheppard, and Seija Junno}

\section{Discussion and Conclusion}

The research question guiding our work has been "What are platform ecosystem options within different global platform economy scenarios?" The results describe a comprehensive set of uncertainties around the development of the platform economy. We have looked at the possible development paths, both on the global level with a focus on national policies and on the industry level from the viewpoint of a consortium of companies. The scenarios and the further robust portfolio analysis help to define actions and strategies that are resilient towards different possibilities. The process described thus produces a set of possible actions, both for policy makers and corporate strategy makers interested in developing platform ecosystems. The results also highlight the need for the resilience of the key actions companies in a platform ecosystem can take to ensure a favourable development in this uncertain environment.

On the methodological side, our article presents a concrete, systematic process to build a vision and strategy options for a new platform ecosystem. The approach is a good example of combining more qualitative results, such as the scenario narratives and key uncertainties, with more quantified methods, such as choosing a robust portfolio of actions.

A shared understanding of the operating environment of an ecosystem and attractive vision are prerequisites for a birth of a new platform ecosystem. The vision should be strong enough that it will motivate ecosystem members with different priorities to overcome the risks generated by the uncertainty of the outcomes. We believe that the systematic process described in this article will help in attaining the shared understanding and create resilient visions. The scenarios and strategies developed in the project are also being used in a set of virtual tools. We are developing a workbook on platform ecosystem development and a web-based game that helps the initiators of the ecosystem in assessing different strategy options.

\section{Acknowledgements}

The research leading to these results has received funding from the Strategic Research Council at the Academy of Finland under grant agreement no. 293446 - Platform Value Now: Value Capturing in the Fast Emerging Platform Ecosystems.

This article was developed from a paper presented at the ISPIM Innovation Conference in Vienna, Austria, June 18-21, 2017. ISPIM (ispim-innovation.com) - the International Society for Professional Innovation Management - is a network of researchers, industrialists, consultants, and public bodies who share an interest in innovation management. 


\section{Anticipating Alternative Futures for the Platform Economy}

Mikko Dufva, Raija Koivisto, Leena Ilmola-Sheppard, and Seija Junno

\section{About the Authors}

Mikko Dufva is a Research Scientist at VTT Technical Research Centre of Finland working in the field of foresight. He has completed projects and research related to the futures of work, the platform economy, synthetic biology, forestry, mining, and the use of renewable energy. He holds a Doctor of Science degree in Technology, and his dissertation was about knowledge creation in foresight from a systems perspective. He has broad methodological expertise ranging from systems thinking, decision analysis, and optimization to interactive planning, scenario analysis, and participatory methods.

Raija Koivisto is a Principal Scientist at VTT Technical Research Centre of Finland. She has over 30 years' experience in research and consultancy in risk management, safety, security, and foresight-related areas. Her main interest is to try to understand and manage phenomena and their impacts on people, organizations, and society by using risk management and foresight methods. Her current research focuses on the platform economy, ethics, pandemic risks in transport hubs, and resilience of infrastructures.

Leena Ilmola-Sheppard is a Senior Research Scholar in the International Institute for Advanced Systems Analysis (IIASA). Her research theme is uncertainty and resilience of social systems. She is developing new modelling methods for foresight and tools for pragmatic decision making. Her current projects include developing management systems for resilience.

Seija Junno is a Director of Business Model Development at SSAB. She was the leader of the SmartSteel project. She has over 30 years of experience in $R \& D$, especially in activating new business development and business models, driving user experience and service business mindset into $R \& D$ and communicating, and making results understandable. She has also been involved in developing the innovation system around metal and steel industry as part of the Finnish Metals and Engineering Competence Cluster Ltd (FIMECC) network program.

\section{References}

Acquier, A., Daudigeos, T., \& Pinkse, J. 2017. Promises and Paradoxes of the Sharing Economy: An Organizing Framework. Technological Forecasting and Social Change (in press). http://doi.org/10.1016/j.techfore.2017.07.006

Autio, E., Thomas, L., \& Gann, D. 2016. Ecosystem Value Co-Creation. I\&E Working Papers. London: Imperial College Business School.

Daft, R. L., \& Weick, K. E. 1984. Toward a Model of Organizations as Interpretation Systems. Academy of Management Review, 9(2): 284-295.

http://doi.org/10.5465/AMR.1984.4277657

Edelman, B. G., \& Geradin, D. 2015. Efficiencies and Regulatory Shortcuts: How Should We Regulate Companies Like Airbnb and Uber. Stanford Technical Law Review, 19: 293-328.

Eloranta, V., \& Turunen, T. 2016. Platforms in Service-Driven Manufacturing: Leveraging Complexity by Connecting, Sharing, and Integrating. Industrial Marketing Management, 55: 178-186. http://doi.org/10.1016/j.indmarman.2015.10.003

Evans, D. S. 2003. Some Empirical Aspects of Multi-sided Platform Industries. Review of Network Economics, 2(3): 191-209. http://doi.org/10.2202/1446-9022.1026

Evans, D. S., Schmalensee, R., Noel, M. D., Chang, H. H., \& GarciaSwartz, D. D. 2011. Platform Economics: Essays on Multi-Sided Businesses. Boston, MA: Competition Policy International.

Folke, C. 2006. Resilience: The Emergence of a Perspective for SocialEcological Systems Analyses. Global Environmental Change, 16(3): 253-267.

http://doi.org/10.1016/j.gloenvcha.2006.04.002

Gawer, A., \& Cusumano, M. A. 2014. Industry Platforms and Ecosystem Innovation. Journal of Product Innovation Management, 31(3): 417-433. http://doi.org/10.1111/jpim.12105

Ilmola, L., \& Kuusi, O. 2013. Information Filters as One of the Means of Managing Strategic Fit in a Complex Environment. Foresight, 15(2): 132-151. http://doi.org/10.1108/14636681311321130

Ilmola, L., \& Rovenskaya, E. 2016. Three Experiments: The Exploration of Unknown Unknowns in Foresight. Technological Forecasting and Social Change, 106: 85-100.

http://doi.org/10.1016/j.techfore.2015.12.015

Lacy, P., Hagenmueller, M., \& Ising, J. 2016. Platform Strategies: How the Rules of Competitiveness Have Changed in the Era of Ecosystems. Chicago, IL: Accenture Strategy.

Liesiö, J., Mild, P., \& Salo, A. 2008. Robust Portfolio Modeling with Incomplete Cost Information and Project Interdependencies. European Journal of Operational Research, 190(3): 679-695. http://doi.org/10.1016/j.ejor.2007.06.049

Lourenço, J. C., Morton, A., \& Bana e Costa, C. A. 2012. PROBE-A Multicriteria Decision Support System for Portfolio Robustness Evaluation. Decision Support Systems, 54(1): 534-550. http://doi.org/10.1016/j.dss.2012.08.001

Murillo, D., Buckland, H., \& Val, E. 2017. When the Sharing Economy Becomes Neoliberalism on Steroids: Unravelling the Controversies. Technological Forecasting and Social Change (in press).

http://doi.org/10.1016/j.techfore.2017.05.024 


\section{Anticipating Alternative Futures for the Platform Economy \\ Mikko Dufva, Raija Koivisto, Leena Ilmola-Sheppard, and Seija Junno}

OECD. 2017. Key Issues for Digital Transformation in the G20: Report Prepared for a Joint G20 German Presidency/OECD Conference. Berlin: Organisation for Economic Co-operation and Development (OECD).

Parker, G. G., Van Alstyne, M. W., \& Choudary, S. P. 2016. Platform Revolution: How Networked Markets Are Transforming the Economy and How to Make Them Work for You. New York: WW Norton \& Company.

Ritchey, T. 2011. General Morphological Analysis (GMA). In Wicked Problems - Social Messes: Decision Support Modelling with Morphological Analysis: 7-18. Berlin, Heidelberg: Springer Berlin Heidelberg.

Taleb, N. N. 2007. The Black Swan: The Impact of the Highly Improbable. New York: Random House.

Thomas, D. W. L., Autio, E., \& Gann, D. M. 2014. Architectural Leverage: Putting Platforms in Context. Academy of Management Perspectives, 28(2): 198-219.

http://doi.org/10.5465/amp.2011.0105

Van Alstyne, M. W., Parker, G. G., \& Choudary, S. P. 2016. Pipelines, Platforms, and the New Rules of Strategy. Harvard Business Review, 94(4): 54-60.

Citation: Dufva, M., Koivisto, R., Ilmola-Sheppard, L., \&

Junno, S. 2017. Anticipating Alternative Futures for the

(cc) BY

Platform Economy. Technology Innovation

Management Review, 7(9): 6-16.

http://doi.org/10.22215/timreview/1102

Keywords: platforms, platform economy, foresight, strategy, scenarios, morphological analysis, portfolio modelling, resilience 